\title{
ANÁLISE ANTROPOMÉTRICA DE TRABALHADORES EM ATIVIDADES DE IMPLANTAÇÃO FLORESTAL
}

\author{
Eduardo da Silva Lopes ${ }^{1}$, Pedro Caldas de Britto $^{2}$, Erivelton Fontana de Laat ${ }^{3}$, Nilton César Fiedler ${ }^{4}$, \\ Thábata Palma Vieira ${ }^{5}$ \\ ${ }^{1}$ Eng. Florestal, Dr., Depto. de Engenharia Florestal, UNICENTRO, Irati, PR, Brasil - eslopes@ pq.cnpq.br \\ ${ }^{2}$ Eng. Florestal, M.Sc., UNICENTRO, Irati, PR, Brasil - pbflorestal@ yahoo.com.br \\ ${ }^{3}$ Eng. Florestal, Dr., Depto. de Educação Física, UNICENTRO, Irati, PR, Brasil - eriveltonlaat@ hotmail.com.br \\ ${ }^{4}$ Eng. Florestal, Dr., Depto. de Ciências Florestais, UFES, Alegre, ES, Brasil - fiedler@pq.cnpq.br \\ ${ }^{5}$ Acadêmica de Engenharia Florestal, UNICENTRO, Irati, PR, Brasil - thabata.vieira@ hotmail.com
}

Recebido para publicação: 01/07/2013 - Aceito para publicação: 03/10/2013

\begin{abstract}
O objetivo deste trabalho foi realizar uma análise antropométrica de trabalhadores em atividades de implantação florestal, visando a melhoria das condições de saúde e segurança. Medidas antropométricas estáticas foram obtidas em uma amostra de 250 trabalhadores florestais que atuavam em uma empresa localizada no estado do Paraná. Os dados foram obtidos na posição em pé, sentado, da cabeça, das mãos e dos pés e analisados por meio do cálculo de percentis. Foram determinados os padrões antropométricos dos trabalhadores florestais, os limites mínimos e máximos das variáveis, e definidas as suas aplicações no dimensionamento de postos de trabalho, equipamentos e algumas ferramentas utilizadas em atividades de implantação florestal. Alguns resultados foram aplicados na análise de uma plantadora e adubadora, sendo que as medidas de altura e comprimento da pega das hastes da plantadora e adubadora não estavam compatíveis com as variáveis antropométricas dos trabalhadores no percentil de $95 \%$, necessitando de ajustes nas ferramentas para evitar problemas de desconforto no trabalho e possíveis danos à saúde e segurança dos trabalhadores.

Palavras-chave: Implantação florestal; antropometria; saúde; segurança.
\end{abstract}

Resumo

\begin{abstract}
Anthropometric analysis of workers in forest planting operations. This research aims to evaluate the anthropometric measures of the workers in forest planting operations, to improve health and safety conditions. We obtained static anthropometric measurements from a sample of 250 forest workers who worked in a company located in Paraná State. The data obtained refers to standing and sitting positions, besides head, hands and feet and analyzed by percentile calculations. It was determined the anthropometrics patterns of workers, the minimum and maximum limits of the variables and select their applications in the design of jobs, equipment and some tools for forest planting activities. Measurements of height and length of the handle stem planter and fertilizer weren't compatible with the anthropometric variables of workers at the $95 \%$ percentile, requiring adjustments to avoid problems of discomfort at work and possible damage to the health and safety of workers.

Keywords: Forest planting; anthropometry; health; safety.
\end{abstract}

\section{INTRODUÇÃO}

Ao contrário da colheita de madeira, que possui máquinas e equipamentos de alta tecnologia e produtividade, a área de silvicultura, especialmente relacionada às atividades de implantação florestal, trabalha com métodos manuais ou semimecanizados, com uso de máquinas e ferramentas adaptadas, envolvendo um grande contingente de mão de obra, cujos trabalhadores realizam normalmente o trabalho em condições ergonômicas inapropriadas.

Além disso, as atividades florestais são de elevada exigência física, em que os trabalhadores podem exercer atividades com grande esforço físico, adotar posturas potencialmente lesivas ao organismo e manusear cargas com pesos acima dos limites toleráveis (TOUPIN et al., 2006; SILVA et al., 2007). 
Tais situações, segundo Iida (2005), poderão comprometer a produtividade, causar desconforto e aumentar os riscos de acidentes e danos à saúde dos trabalhadores.

De acordo com Brito et al. (2011), o ser humano é capaz de adaptar-se facilmente às diversas situações impostas por máquinas e ferramentas mal projetadas, sendo que, normalmente, as posições inadequadas e incômodas são suportadas pelos trabalhadores. Porém essas situações poderão prejudicar a médio e longo prazo a produtividade e causar danos irreversíveis à saúde dos trabalhadores. Por isso, no correto dimensionamento do posto de trabalho, máquinas ou ferramentas devem considerar a postura, o alcance dos comandos e as características antropométricas dos trabalhadores (IIDA, 2005).

A antropometria é o estudo das medidas humanas, sendo que o conhecimento dessas medidas e saber como usá-las é importante na determinação dos diversos aspectos relacionados ao posto de trabalho, de modo a permitir ao trabalhador manter uma boa postura (COUTO, 2007). Segundo Iida (1990), a antropometria pode ser classificada em estática, dinâmica e funcional. Os dados da antropometria estática servem como primeira aproximação para o dimensionamento de produtos ou postos de trabalho ou para situações em que os movimentos corporais são pequenos, sendo necessária posteriormente a realização de ajustes para acomodação dos movimentos corporais. Caso os movimentos já sejam previamente definidos, podem-se usar dados da antropometria dinâmica, de modo que o projeto esteja o mais próximo possível das condições reais. Por fim, quando os movimentos corporais são realizados simultaneamente, modificando os alcances em relação aos valores da antropometria dinâmica, faz-se uso da antropometria funcional. Fernandes et al. (2009) registram ainda que os dados antropométricos são expressos em percentis, significando parte da população cuja medida é inferior ou superior a um determinado valor.

As medidas antropométricas são ainda informações de grande importância para a concepção de projetos ou correção dos meios de produção, como postos de trabalho, equipamentos ou ferramentas, capazes de satisfazer ergonomicamente os trabalhadores do ponto de vista do conforto, da saúde e da segurança. Minette et al. (2002) relatam que, quando as máquinas, equipamentos ou ferramentas se adaptam adequadamente ao organismo, o desconforto, a fadiga, os erros e os acidentes diminuem sensivelmente.

Por outro lado, é importante afirmar que, no Brasil, há uma grande carência de dados antropométricos disponíveis relativos à população brasileira, principalmente aplicados às atividades florestais, que utilizam grande contingente de mão de obra, bem como faltam normas técnicas para algumas máquinas e ferramentas florestais, que permitissem a concepção de novos projetos ou correção dos problemas existentes. Segundo Schlosser et al. (2002), a maioria dos dados disponíveis foi utilizada no desenvolvimento de projetos de tratores agrícolas e obtidos a partir de indivíduos estrangeiros, devido à carência de informações antropométricas de operadores brasileiros.

Portanto, a obtenção de dados e a construção de tabelas antropométricas de trabalhadores de diferentes regiões do país poderão contribuir de forma evidente com os fabricantes e gestores florestais, subsidiando a concepção de novos projetos e a solução de problemas de adequação de postos de trabalho, equipamentos e ferramentas. Tal fato torna-se mais evidente principalmente no Brasil, que, por ser um país de grandes dimensões e possuir uma população com características físicas muito variáveis, dificulta ainda mais o levantamento e utilização de dados antropométricos.

Objetivou-se, neste trabalho, realizar uma análise antropométrica de trabalhadores em atividades de implantação florestal em uma empresa localizada no estado do Paraná, determinando o seu padrão antropométrico, os limites de percentis das variáveis estudadas e sua aplicação no dimensionamento de postos de trabalho, equipamentos e ferramentas florestais.

\section{MATERIAL E MÉTODOS}

\section{Área de estudo}

O trabalho foi realizado em uma empresa que atuava na prestação de serviços de implantação e manutenção de plantios florestais, localizada na região dos Campos Gerais, Paraná.

O clima predominante da região de estudo é, segundo a classificação de Köppen, subtropical (Cfa), com temperatura média anual no mês mais frio inferior a $18{ }^{\circ} \mathrm{C}$ e temperatura média no mês mais quente acima de $22{ }^{\circ} \mathrm{C}$, com verões quentes, geadas pouco frequentes e tendência de concentração das chuvas nos meses de verão, contudo sem estação seca definida. O relevo da região estudada é bastante diversificado, possuindo áreas planas a forte-ondulado. 


\section{População pesquisada}

A população estudada foi composta por 250 trabalhadores florestais que atuavam nas atividades silviculturais de plantio, adubação e capina química, compreendendo $100 \%$ dos trabalhadores que atuavam na região de estudo.

Para realização do estudo, todos os trabalhadores participantes receberam esclarecimentos sobre a metodologia e os objetivos da pesquisa, por meio da leitura e assinatura do Termo de Consentimento Livre e Esclarecido (TCLE), conforme preceitua a Resolução 466/2012 do Conselho Nacional de Saúde do Ministério da Saúde (CNS, 2012).

\section{Coleta de dados}

Inicialmente, foram obtidas 41 medidas antropométricas estáticas dos trabalhadores em posições padronizadas, sendo 13 medidas do corpo em pé, 13 do corpo sentado, cinco da cabeça, sete das mãos e três dos pés, resumidas da Norma Alemã DIN 33402/81, citada por IIDA (1990), de modo a determinar os padrões antropométricos dos trabalhadores florestais da região de estudo. As medidas antropométricas foram obtidas por medição direta com uso de uma cadeira antropométrica, antropômetro e fita métrica, construídos a partir de modelo proposto por Couto (1995), sendo os dados coletados no próprio local de trabalho (Figura 1).

Fonte: Adaptado de Couto (1995).

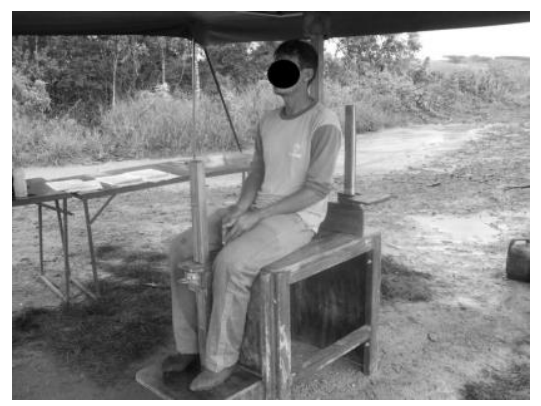

Figura 1. Medição do trabalhador na posição sentada.

Figure 1. Measuring of worker seating.

De posse das medidas obtidas, foram selecionadas as variáveis antropométricas dos trabalhadores que possuíam relação direta com as atividades de implantação florestal, compreendidas pelas medidas do corpo em pé, da cabeça, das mãos e dos pés. Foram determinados os limites de percentis mínimos e máximos das variáveis, as medidas obtidas e sua aplicação no dimensionamento de algumas situações relacionadas a postos de trabalho, máquinas, ferramentas e equipamentos de proteção individual.

Por fim, foram selecionadas as variáveis antropométricas que possuíam relação direta com as medidas de uma plantadora e adubadora utilizadas nas atividades de plantio e adubação, respectivamente, com a finalidade de verificar se as medidas das ferramentas estavam adequadas ao perfil antropométrico da população de trabalhadores florestais da região de estudo.

Na figura 2 são mostradas as principais medidas da plantadora utilizada nas atividades de plantio de florestas e que possui relação direta com as variáveis e medidas antropométricas dos trabalhadores.

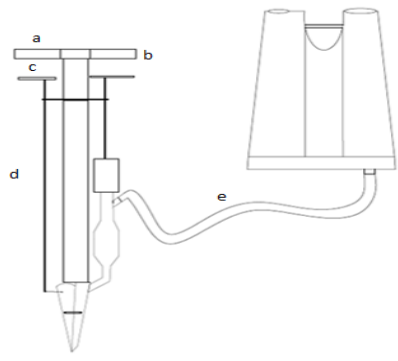

(a) comprimento da pega do cabo: $11 \mathrm{~cm}$; (b) diâmetro da pega do cabo: $2,5 \mathrm{~cm}$; (c) distância entre a pega e o gatilho: 6,0 cm; (d) altura da haste em relação ao solo: 79,0 cm; (e) comprimento da mangueira entre o recipiente costal e a plantadora (variável).

Figura 2. Medidas obtidas da plantadora florestal.

Figure 2. Measurements of forest plantation. 
O diagrama representativo da adubadora e as principais medidas a serem consideradas para o correto dimensionamento da ferramenta são mostrados na figura 3.

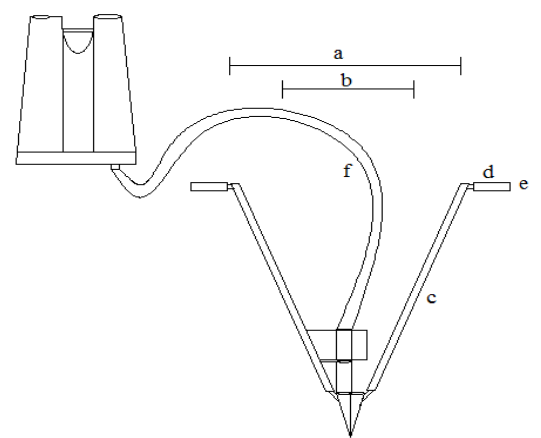

(a) abertura máxima da ferramenta: $\mathrm{o} /, \mathrm{J} \mathrm{cm}$; (b) abertura mınıma da terramenta: $39,5 \mathrm{~cm}$; (c) altura da haste em relação ao solo: 71 cm; (d) comprimento da pega do cabo: 10,9 cm; (e) diâmetro da pega do cabo: $2,5 \mathrm{~cm}$; (f) comprimento da mangueira entre o recipiente costal e a plantadora (variável).

Figura 3. Medidas obtidas da adubadora florestal.

Figure 3. Measurements of forest fertilizer.

A análise estatística foi realizada com uso dos percentis 5, 50 e 95\%, por meio da seguinte equação:

$$
\mathrm{Pi}=\left(\frac{\mathrm{i}}{100}\right) * \mathrm{n}
$$

Em que: $\mathrm{i}=$ percentil desejado;

$\mathrm{n}=$ total da frequência acumulada $\left(\mathrm{n}^{\mathrm{o}}\right.$ total de pessoas na amostra).

\section{RESULTADOS E DISCUSSÃO}

\section{Padrão antropométrico dos trabalhadores}

Os resultados do padrão antropométrico dos trabalhadores florestais em relação às variáveis estáticas nos percentis 5, 50 e $95 \%$ são apresentados na tabela 1 . Como pode ser visto, $90 \%$ dos trabalhadores estudados possuíam estatura entre $156,8 \mathrm{~cm}$ e $178,8 \mathrm{~cm}$, podendo tais medidas ser aplicadas, por exemplo, como referência no dimensionamento de postos de trabalho. É importante ressaltar que tais medidas são definidas em faixas entre um mínimo e um máximo, representadas pelos percentis de 5 e $95 \%$, respectivamente, com intervalo de confiança de $90 \%$.

Alves (2001), estudando trabalhadores de um viveiro florestal em uma empresa da região do Vale do Rio Doce, Minas Gerais, encontrou valores de estatura que variaram de 152,5 a 180,0 cm para os percentis de 5 e $95 \%$, respectivamente. Já Fontana e Seixas (2007) encontraram diferenças nos dados antropométricos da população de trabalhadores florestais, quando comparados com o biótipo de trabalhadores norte-americanos e europeus.

Portanto, verifica-se a importância da obtenção de dados e a construção de tabelas antropométricas para trabalhadores de diferentes regiões, principalmente no Brasil, que possui grandes dimensões e uma população de diferentes etnias e características físicas muito variáveis.

Além disso, deve-se ressaltar que o uso das faixas de percentis depende do tipo de projeto, das aplicações e finalidade das medidas e da população dos futuros usuários do produto. Conforme relatado por Schlosser et al. (2002), tais informações são importantes, pois podem ocorrer variações no padrão antropométrico dentro de um mesmo país, conforme a região estudada.

É importante destacar que, na empresa estudada, havia uma frequente troca de funções entre os trabalhadores, em que muitos atuavam em duas ou mais atividades, devido à necessidade de execução de uma atividade em determinada época do ano. Portanto, tal situação demonstra a importância da determinação do perfil antropométrico dos trabalhadores, cujas informações poderão auxiliar os gestores na concepção de postos de trabalho, máquinas, equipamentos e ferramentas que sejam mais adequados ao conforto, saúde e segurança dos trabalhadores. 
Tabela 1. Padrão antropométrico dos trabalhadores florestais.

Table 1. Anthropometric standard of the forestry workers.

\begin{tabular}{|c|c|c|c|c|c|c|c|c|}
\hline \multirow{2}{*}{\multicolumn{3}{|c|}{ Variável antropométrica }} & \multicolumn{3}{|c|}{ Percentil (cm) } & \multirow{2}{*}{$\begin{array}{l}\text { Média } \\
(\mathbf{c m})\end{array}$} & \multirow{2}{*}{$\begin{array}{c}\text { DP } \\
(\mathrm{cm})\end{array}$} & \multirow{2}{*}{$\begin{array}{l}\mathrm{CV} \\
(\%)\end{array}$} \\
\hline & & & \multirow{2}{*}{$\begin{array}{c}\mathbf{5 \%} \\
156,8\end{array}$} & \multirow{2}{*}{$\begin{array}{l}\mathbf{5 0 \%} \\
167,0\end{array}$} & \multirow{2}{*}{$\begin{array}{l}\mathbf{9 5 \%} \\
178,5\end{array}$} & & & \\
\hline \multirow{13}{*}{ 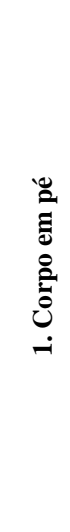 } & 1.1 & Estatura do corpo ereto & & & & 167,2 & 6,4 & 4,0 \\
\hline & 1.2 & Altura dos olhos em pé & 145,1 & 155,3 & 164,0 & 155,1 & 5,9 & 4,0 \\
\hline & 1.3 & Altura dos ombros & 129,0 & 138,4 & 149,0 & 143,7 & 5,9 & 4,0 \\
\hline & 1.4 & Altura do cotovelo & 94,0 & 102,2 & 111,0 & 102,1 & 5,0 & 5,0 \\
\hline & 1.5 & Altura do centro da mão com o braço pendido & 68,1 & 75,0 & 81,2 & 75,0 & 4,3 & 6,0 \\
\hline & 1.6 & Altura do centro da mão com o braço erguido & 185,7 & 199,0 & 214,3 & 196,4 & 8,7 & 4,0 \\
\hline & 1.7 & Comprimento braço horizontal ao centro da mão & 51,8 & 58,0 & 64,8 & 58,1 & 4,0 & 7,0 \\
\hline & 1.8 & Profundidade do corpo na altura do tórax & 19,9 & 22,8 & 26,0 & 23,6 & 2,0 & 9,0 \\
\hline & 1.9 & Largura dos ombros em pé & 32,0 & 35,3 & 39,5 & 37,0 & 3,2 & 9,0 \\
\hline & 1.10 & Altura linha mamilar & 114,6 & 123,3 & 133,3 & 123,8 & 6,0 & 5,0 \\
\hline & 1.11 & Largura dos quadris em pé & 26,7 & 30,2 & 34,2 & 30,6 & 2,4 & 8,0 \\
\hline & 1.12 & Altura do umbigo & 93,5 & 102,0 & 112,0 & 101,3 & 5,5 & 5,0 \\
\hline & 1.13 & Altura do púbis & 69,0 & 85,3 & 96,5 & 84,6 & 8,0 & 9,0 \\
\hline \multirow{13}{*}{ 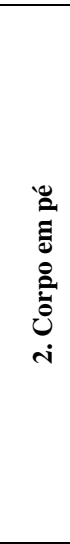 } & 2.1 & Altura da cabeça a partir do assento com o tronco ereto & 80,3 & 86,4 & 91,7 & 85,7 & 3,7 & 4,0 \\
\hline & 2.2 & Altura dos olhos a partir do assento & 67,3 & 74,3 & 80,6 & 74,0 & 4,2 & 6,0 \\
\hline & 2.3 & Altura dos ombros a partir do assento & 52,0 & 57,0 & 63,0 & 57,3 & 3,9 & 7,0 \\
\hline & 2.4 & Altura do cotovelo a partir do assento & 19,0 & 22,5 & 28,0 & 22,8 & 2,8 & 12,0 \\
\hline & 2.5 & Altura do joelho sentado & 47,5 & 53,0 & 59,0 & 53,1 & 4,2 & 8,0 \\
\hline & 2.6 & Altura poplítea (parte inferior da coxa) & 39,5 & 44,0 & 49,0 & 44,3 & 2,9 & 7,0 \\
\hline & 2.7 & $\begin{array}{l}\text { Comprimento do antebraço na horizontal até o centro } \\
\text { da mão }\end{array}$ & 23,0 & 27,0 & 32,5 & 28,5 & 2,8 & 10,0 \\
\hline & 2.8 & Comprimento nádega-poplítea & 43,0 & 47,5 & 52,5 & 47,8 & 2,8 & 6,0 \\
\hline & 2.9 & Comprimento nádega-joelho & 540 & 58,0 & 64,0 & 58,5 & 3,1 & 5,0 \\
\hline & 2.10 & Comprimento nádega-pé & 93,0 & 101,0 & 110,0 & 99,7 & 5,6 & 6,0 \\
\hline & 2.11 & Altura da parte superior da coxa & 11,0 & 13,6 & 16,0 & 14,9 & 1,5 & 11,0 \\
\hline & 2.12 & Largura entre os cotovelos & 30,5 & 37,5 & 45,0 & 38,0 & 4,1 & 11,0 \\
\hline & 2.13 & Largura dos quadris sentado & 25,5 & 30,0 & 34,3 & 30,1 & 2,9 & 10,0 \\
\hline \multirow{5}{*}{ 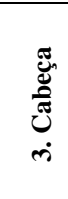 } & 3.1 & Comprimento vertical da cabeça & 20,3 & 22,0 & 24,1 & 22,4 & 1,2 & 6,0 \\
\hline & 3.2 & Largura da cabeça de frente & 14,3 & 15,2 & 16,4 & 15,2 & 0,7 & 5,0 \\
\hline & 3.3 & Largura da cabeça de perfil & 17,3 & 18,6 & 20,0 & 19,3 & 0,9 & 5,0 \\
\hline & 3.4 & Distância entre os olhos & 5,1 & 6,1 & 7,8 & 6,4 & 0,9 & 14,0 \\
\hline & 3.5 & Circunferência da cabeça & 52,5 & 55,0 & 57,7 & 54,5 & 1,6 & 3,0 \\
\hline \multirow{7}{*}{ 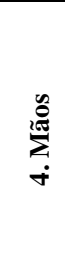 } & 4.1 & Comprimento da mão & 16,9 & 18,3 & 20 & 18,3 & 1,0 & 5,0 \\
\hline & 4.2 & Largura da mão & 9,3 & 10,5 & 11,7 & 10,5 & 0,8 & 8,0 \\
\hline & 4.3 & Comprimento da palma da mão & 9,2 & 10,3 & 11,5 & 10,3 & 0,7 & 7,0 \\
\hline & 4.4 & Largura da palma da mão & 7,6 & 9,0 & 10,0 & 8,9 & 0,7 & 8,0 \\
\hline & 4.5 & Circunferência da palma & 21,5 & 24,5 & 26,8 & 24,2 & 1,6 & 6,0 \\
\hline & 4.6 & Circunferência do pulso & 15,6 & 17,0 & 18,8 & 17,1 & 0,9 & 6,0 \\
\hline & 4.7 & Cilindro de pega máxima (diâmetro) & 2,5 & 4,0 & 5,0 & 3,8 & 0,7 & 18,0 \\
\hline \multirow{3}{*}{$\stackrel{\mathscr{8}}{\stackrel{8}{10}}$} & 5.1 & Comprimento do pé & 22,7 & 25 & 27,3 & 24,9 & 1,4 & 5,0 \\
\hline & 5.2 & Largura do pé & 8,3 & 9,5 & 10,7 & 9,8 & 0,8 & 8,0 \\
\hline & 5.3 & Largura do calcanhar & 5,8 & 6,9 & 8,7 & 7,0 & 0,9 & 12,0 \\
\hline
\end{tabular}

CV: coeficiente de variação; DP: desvio padrão.

Por outro lado, as atividades silviculturais são dinâmicas, com os trabalhadores adotando diversas posturas, com o corpo realizando movimentos em diversos ângulos e aplicando forças variáveis ao longo da jornada de trabalho, e mesmo as medidas sendo estáticas, poderão contribuir com a melhoria das condições de trabalho. 


\section{Aplicação das variáveis antropométricas}

A tabela 2 apresenta as variáveis antropométricas dos trabalhadores, algumas aplicações nas atividades de implantação florestal, o percentil utilizado em cada situação e as medidas corporais correspondentes, sendo que muitas das variáveis antropométricas selecionadas apresentaram relações comuns com as atividades de implantação florestal.

Dentre as medidas obtidas, a estatura do corpo ereto possui grande aplicação no dimensionamento da altura mínima de passagens e portas em ambiente florestal, como casas de vegetação em viveiros florestais, instalações diversas no campo (escritório, bancas para refeições, banheiros etc.), portas de acesso às máquinas etc., devendo, nesse caso, ser adotado como critério o percentil de $95 \%$ $(178,5 \mathrm{~cm})$, de forma a atender à maioria dos trabalhadores.

As variáveis largura e altura dos ombros são medidas importantes para definição do dimensionamento mínimo e máximo de equipamentos e ferramentas de uso costal, como os recipientes para armazenamento de hidrogel, fertilizantes e herbicidas, devendo neste caso ser adotados os percentis 5 e $95 \%$, de forma que os equipamentos estejam ajustados, confortavelmente, às medidas corporais de $90 \%$ dos trabalhadores florestais.

No caso da altura do centro da mão com o braço pendido $(81,2 \mathrm{~cm})$ e braço erguido $(185,7 \mathrm{~cm})$, devem ser adotados os percentis de 95 e $5 \%$, respectivamente, podendo as medidas ser utilizadas na determinação do alcance inferior e superior máximo de dispositivos e controles em postos de trabalho.

Entretanto, é importante ressaltar que, mesmo a altura do centro da mão com o braço pendido sendo uma medida antropométrica estática, ela poderá ser utilizada como referência para o ajuste do comprimento da haste de equipamentos e ferramentas, como motocoveadores, plantadoras, adubadoras etc., em função da falta de uma medida exata que possibilite o correto dimensionamento de equipamentos e ferramentas portáteis. Nesse caso, devem ser adotados os percentis 5 e 95\%, que, para a população estudada, correspondeu às medidas de 68,1 e $81,2 \mathrm{~cm}$.

No caso das alturas do cotovelo e do púbis dos trabalhadores na posição em pé, tais variáveis permitem o dimensionamento de postos de trabalho para a realização de diversas atividades, como canteiros suspensos de viveiros florestais, bancadas para manutenção de máquinas e equipamentos etc. Neste caso, deverá ser adotado o percentil de $95 \%$, ou seja, 111,0 ou $96,5 \mathrm{~cm}$ para as medidas do cotovelo e do púbis, auxiliando o dimensionamento de bancadas onde serão realizados trabalhos leves ou pesados, respectivamente. No caso de trabalhadores de menor estatura, a altura poderá ser corrigida com a instalação de um estrado, sendo uma medida de baixo custo e de fácil adaptação pelos trabalhadores.

Conforme relatado por Minette et al. (2002), as dimensões que se referem às extremidades do corpo, separadamente e dentro dos seus limites, são variáveis cuja aplicação se destina ao dimensionamento de equipamentos de proteção individual (EPIs), podendo ser exemplificado pela cabeça (do topo da cabeça ao queixo), mão (do pulso à extremidade do dedo médio) e pé (do calcanhar à extremidade do dedo).

Apesar da grande variedade de produtos disponíveis no mercado (botas, luvas, óculos de proteção, capacetes, perneiras etc.), é comum a ocorrência de reclamações por parte dos trabalhadores florestais em relação aos incômodos causados pelos EPIs durante o trabalho, conforme relatado por diversos autores (FIEDLER, et al., 2012; LOPES, et al., 2011; FIEDLER, et al., 2000).

Em relação ao comprimento e largura total das mãos e da palma das mãos, tais medidas podem ser utilizadas, por exemplo, no correto dimensionamento de luvas de proteção, devendo nesse caso, ser adotados os percentis 5 e $95 \%$, de forma a atender a $90 \%$ da população. Em relação aos trabalhadores estudados, deverão ser adotadas como referência as medidas do comprimento $(16,9$ a $20 \mathrm{~cm})$ e largura (9,3 a $11,7 \mathrm{~cm})$ das mãos, comprimento $(9,2$ a $11,5 \mathrm{~cm})$ e largura da palma $(7,6$ a $10 \mathrm{~cm})$ das mãos, de modo a auxiliar os ajustes no tamanho e formato das luvas.

Para o comprimento e largura dos pés e largura do calcanhar, deverão ser adotados os percentis 5 e $95 \%$, podendo nesse caso ser utilizados os valores de 22,7 a $27,3 \mathrm{~cm} ; 8,3$ a 10,7 e 5,8 a $8,7 \mathrm{~cm}$, respectivamente. Tais medidas são importantes no ajuste de sapatos de proteção e como proposta para alteração de seu formato com vistas a oferecer maior conforto e segurança aos trabalhadores florestais.

Por fim, as medidas referentes à cabeça (comprimento vertical, largura de frente, largura de perfil e circunferência) poderão ser utilizadas para a adequação de capacetes e bonés de proteção, devendo ser adotados os percentis de 5 e $95 \%$, ou seja, valores entre 20,3 e 24,1 cm; 14,3 e 16,4 cm; 17,3 e $20 \mathrm{~cm} ; 52,5$ e $57,7 \mathrm{~cm}$, respectivamente. 
Tabela 2. Aplicação das variáveis antropométricas dos trabalhadores em atividades florestais.

Table 2. Application of anthropometric variables of workers in forestry activities.

\begin{tabular}{|c|c|c|c|c|}
\hline & Variável antropométrica & Aplicação florestal & $\begin{array}{c}\text { Percentil } \\
\text { utilizado }(\%)\end{array}$ & $\begin{array}{c}\text { Medida } \\
\text { Obtida }(\mathbf{c m})\end{array}$ \\
\hline \multirow{10}{*}{ 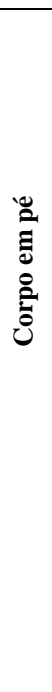 } & Estatura do corpo ereto & $\begin{array}{c}\text { Determinação da altura mínima para passagens e } \\
\text { portas. }\end{array}$ & 95 & 178,5 \\
\hline & Altura dos olhos em pé & $\begin{array}{l}\text { Determinação do ângulo superior e inferior de } \\
\text { visibilidade nos planos frontal e sagital. }\end{array}$ & 5 e 95 & 145,1 a 164,0 \\
\hline & Largura dos ombros em pé & $\begin{array}{l}\text { Determinação da distância máxima entre as pegas do } \\
\text { cabo de equipamentos e ferramentas. }\end{array}$ & 5 e 95 & 32,0 a 39,5 \\
\hline & Altura dos ombros & $\begin{array}{l}\text { Determinação da altura mínima e máxima para o } \\
\text { apoio de equipamentos e ferramentas de uso costal. }\end{array}$ & 5 e 95 & 129,0 a 149,0 \\
\hline & $\begin{array}{l}\text { Altura do centro da mão com } \\
\text { o braco pendido }\end{array}$ & $\begin{array}{c}\text { Determinação do alcance inferior máximo de } \\
\text { objetos. }\end{array}$ & 95 & 81,2 \\
\hline & & $\begin{array}{l}\text { Determinação da altura da haste de equipamentos e } \\
\text { ferramentas em relação ao solo. }\end{array}$ & 5 e 95 & 68,1 a 81,2 \\
\hline & $\begin{array}{l}\text { Altura do centro da mão com } \\
\text { o braço erguido }\end{array}$ & $\begin{array}{c}\text { Determinação do alcance superior máximo de } \\
\text { objetos. }\end{array}$ & 5 & 185,7 \\
\hline & $\begin{array}{l}\text { Comprimento do braço } \\
\text { horizontal ao centro da mão }\end{array}$ & $\begin{array}{l}\text { Determinação da distância máxima de alcance } \\
\text { horizontal de insumos. } \\
\end{array}$ & 5 & 51,8 \\
\hline & Altura do cotovelo & $\begin{array}{l}\text { Determinação da altura de banca para trabalho leve } \\
\text { de manutenção de equipamentos e ferramentas. }\end{array}$ & 95 & 111,0 \\
\hline & Altura dos púbis & $\begin{array}{c}\text { Determinação da altura de banca para trabalho } \\
\text { pesado de manutenção de equipamentos e } \\
\text { ferramentas. }\end{array}$ & 95 & 96,5 \\
\hline \multirow{9}{*}{ 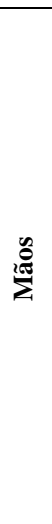 } & Comprimento da mão & $\begin{array}{l}\text { Determinação da distância de abertura entre a pega } \\
\text { do cabo e o gatilho de acionamento de equipamentos } \\
\text { e ferramentas. }\end{array}$ & 5 & 16,9 \\
\hline & & $\begin{array}{l}\text { Determinação do alcance dos dedos para } \\
\text { dimensionamento de luvas de proteção. }\end{array}$ & 5 e 95 & 16,9 a 20,0 \\
\hline & Largura da mão & $\begin{array}{l}\text { Determinação do comprimento da pega do cabo de } \\
\text { equipamentos e ferramentas. }\end{array}$ & 95 & 11,7 \\
\hline & & Determinação das dimensões de luvas de proteção. & 5 e 95 & 9,3 a 11,7 \\
\hline & $\begin{array}{l}\text { Comprimento da palma da } \\
\text { mão }\end{array}$ & Determinação das dimensões de luvas de proteção. & 5 e 95 & 9,2 a 11,5 \\
\hline & Largura da palma da mão & Determinação das dimensões de luvas de proteção. & 5 e 95 & 7,6 a 10,0 \\
\hline & Circunferência da mão. & Determinação das dimensões de luvas de proteção. & 5 e 95 & 21,5 a 24,5 \\
\hline & Circunferência do pulso & Determinação das dimensões de luvas de proteção. & 5 e 95 & 15,6 a 17,0 \\
\hline & $\begin{array}{l}\text { Cilindro de pega máxima } \\
\text { (diâmetro) }\end{array}$ & $\begin{array}{c}\text { Determinação do diâmetro da pega do cabo de } \\
\text { equipamentos e ferramentas. }\end{array}$ & 5 & 2,5 \\
\hline \multirow{3}{*}{$\ddot{\mathscr{E}}$} & Comprimento do pé & Determinação das dimensões de botas de proteção. & 5 e 95 & 22,7 a 27,3 \\
\hline & Largura do pé & Determinação das dimensões de botas de proteção. & 5 e 95 & 8,3 a 10,7 \\
\hline & Largura do calcanhar & Determinação das dimensões de botas de proteção. & 5 e 95 & 5,8 a 8,7 \\
\hline \multirow{5}{*}{ 迎 } & $\begin{array}{l}\text { Comprimento vertical da } \\
\text { cabeca }\end{array}$ & $\begin{array}{l}\text { Dimensionamento das dimensões de capacetes e } \\
\text { bonés de protecão. }\end{array}$ & 5 e 95 & 20,3 a 24,1 \\
\hline & Largura da cabeça de frente & $\begin{array}{c}\text { Determinação das dimensões de capacetes e bonés } \\
\text { de proteção. }\end{array}$ & 5 e 95 & 14,3 a 16,4 \\
\hline & Largura da cabeça de perfil & $\begin{array}{l}\text { Determinação das dimensões de capacetes e bonés } \\
\text { de proteção. }\end{array}$ & 5 e 95 & 17,3 a 20,0 \\
\hline & Distância entre os olhos & $\begin{array}{l}\text { Determinação da largura de óculos e máscaras de } \\
\text { proteção. }\end{array}$ & 5 e 95 & 5,1 a 7,8 \\
\hline & Circunferência da cabeça & $\begin{array}{l}\text { Determinação do diâmetro de capacetes e bonés de } \\
\text { proteção. }\end{array}$ & 5 e 95 & 52,5 a 57,7 \\
\hline
\end{tabular}

Tais recomendações têm grande aplicação para as empresas da região de estudo, mas, devido à grande extensão do país e às diferentes etnias e características físicas variáveis existentes, recomenda-se a construção de tabelas antropométricas para as outras regiões do país.

\section{Análise das medidas de algumas ferramentas florestais}

A altura da plantadora, representada pela altura da haste em relação ao solo $(79,0 \mathrm{~cm})$ não atendeu à medida antropométrica dos trabalhadores no percentil $95 \%(81 \mathrm{~cm})$, devendo tal medida da ferramenta ser corrigida. Nesse caso, a haste da ferramenta poderá possuir uma regulagem com variação 
de 68 a $81 \mathrm{~cm}$ de altura, de forma a atender, no mínimo, a 90\% dos trabalhadores florestais para que desenvolvam um trabalho com maior conforto.

É importante ressaltar que o plantio é uma atividade dinâmica, onde os trabalhadores realizavam diversos movimentos durante o trabalho, tendo sido observado uma leve flexão do braço e antebraço durante a execução da atividade. Apesar dessa situação, a altura do braço pendido é uma variável antropométrica importante que poderá ser utilizada como referência no dimensionamento da altura da ferramenta, contribuindo para a minimização de possíveis desconfortos no trabalho e danos à saúde dos trabalhadores.

Em relação às medidas obtidas entre a pega do cabo e o gatilho $(6,0 \mathrm{~cm})$ e o diâmetro da pega do cabo $(2,5 \mathrm{~cm})$ da plantadora, verificou-se que tais medidas estavam dentro do padrão antropométrico dos trabalhadores florestais estudados, não causando problemas na execução do trabalho. Já em relação ao comprimento da pega do cabo $(11,0 \mathrm{~cm})$, verificou-se que tal medida não estava adequada aos trabalhadores no percentil $95 \%$, necessitando que o comprimento seja alterado, possuindo um comprimento mínimo de $12,0 \mathrm{~cm}$, de forma a atender a $95 \%$ da população de trabalhadores florestais.

Por fim, em relação à mangueira de conexão entre a plantadora e o recipiente costal de hidrogel, verificou-se que tal medida não causou problemas aos trabalhadores. Tal fato deve-se à existência de regulagem da mangueira, que permitiu que os trabalhadores fizessem os ajustes necessários de acordo com as suas medidas antropométricas.

É importante observar que a abertura máxima e mínima da haste da adubadora não pode ser avaliada somente com o uso da antropometria estática, pois suas medidas não estão diretamente relacionadas a uma única variável antropométrica, mas a um conjunto de diferentes segmentos do corpo (comprimento dos braços e antebraços). Apesar disso, a largura dos ombros dos trabalhadores em pé poderá ser utilizada como referência na determinação da distância máxima de abertura entre as pegas do cabo da adubadora, evitando assim a abertura excessiva dos braços durante a execução do trabalho, com possível desconforto e danos à saúde dos trabalhadores.

A altura da adubadora, representada pela distância entre a pega e o solo, foi também relacionada com a medida da altura do braço pendido, podendo tal variável ser utilizada para definição da medida inferior máxima da ferramenta. Nesse caso, a altura da adubadora $(71,0 \mathrm{~cm})$ não atendeu à medida antropométrica dos trabalhadores no percentil $95 \%(81,0 \mathrm{~cm})$. Além disso, é importante salientar que os trabalhadores utilizavam a adubadora à frente do corpo, com movimentos verticais para deposição do fertilizante e movimentos horizontais de abertura e fechamento da haste da ferramenta, acarretando a inclinação da coluna vertebral, principalmente nos trabalhadores de maior estatura, com possíveis desconfortos na execução do trabalho e danos à saúde.

Em relação ao diâmetro da pega da ferramenta $(2,5 \mathrm{~cm})$, relacionada com a variável cilindro de pega, verificou-se que tal medida estava adequada às características antropométricas dos trabalhadores no percentil 5\%. Já o comprimento da pega $(11 \mathrm{~cm})$, relacionada com a largura das mãos não estava adequado ao percentil 95\%, demonstrando, nesse caso, a necessidade de ajustes na pega do cabo para um comprimento mínimo de $12 \mathrm{~cm}$.

Por fim, verificou-se que o comprimento da mangueira que faz a conexão entre o recipiente costal e a adubadora também não causava problemas de desconforto aos trabalhadores, em função da existência de regulagem na mangueira, que permitia a realização de ajuste da ferramenta às medidas antropométricas dos trabalhadores.

\section{CONCLUSÕES}

- A construção de tabelas antropométricas para trabalhadores florestais de diferentes regiões do país poderá contribuir com os fabricantes e gestores na concepção de projetos de postos de trabalho, equipamentos e ferramentas, contribuindo para a melhoria das condições de conforto, saúde e segurança e produtividade das operações florestais.

- A altura do braço pendido mostrou-se uma variável antropométrica que poderá ser utilizada como referência para o dimensionamento das hastes de ferramentas, de forma a minimizar possíveis desconfortos no trabalho e danos à saúde dos trabalhadores.

- As medidas de altura e comprimento da pega da haste da plantadora e adubadora não estavam compatíveis com as medidas antropométricas dos trabalhadores no percentil de $95 \%$, necessitando a realização de ajustes nas medidas dessas ferramentas florestais. 


\section{AGRADECIMENTO}

Ao CNPq, pelo apoio financeiro, e à empresa, pela cessão da área de estudo.

\section{REFERÊNCIAS}

ASSOSIAÇÃO BRASILEIRA DE PRODUTORES DE FLORESTAS PLANTADAS (ABRAF). Anuário Estatístico da ABRAF - 2012: Ano base 2011. p. 149.

ALVES, J. U. Avaliação do perfil e condições de trabalho de operários na atividade de propagação de Eucalyptus spp. em viveiros. 106 f. Dissertação (Mestrado em Ciência Florestal) - Universidade Federal de Viçosa. Viçosa, 2001.

BRITO, A. B.; MINETTE, L. J.; SOUZA, A. P.; FERNANDES, H. C. Design e ergonomia no desenvolvimento de ferramentas e equipamentos florestais e agrícolas. In: MINETTE, L. J.; SOUZA, A. P. Ergonomia e Segurança no Trabalho Florestal e Agrícola 3. Visconde do Rio Branco: Suprema, 2011.p. 89 - 08.

CONSELHO NACIONAL DE SAÚDE. Resolução no 466, de 12 de dezembro de 2012. Disponível em: <http://www.conselho.saude.gov.br/resolucoes/2012/Reso466.pdf〉. Acesso em: 30/06/2013.

COUTO, H. de A. Ergonomia aplicada ao trabalho - O manual técnico da máquina humana. Belo Horizonte: Ergo, 1995. 383 p.

FERNANDES, H. C.; BRITO, A. B.; SANTOS, N. T.; MINETTE, L. J.; RINALDI, P. C. N. Análise antropométrica de um grupo de operadores brasileiros de "feller buncher". Scientia Forestalis. v. 37, n. 81, p. 17 - 25, 2009.

FIEDLER, N. C.; SILVA, E. N.; MAZIERO, R.; JUVANHOL, R. S.; GONÇALVES, S. B. Caracterização de fatores humanos e análise das condições de trabalho em atividades de implantação de florestas de produção. Revista Científica Eletrônica de Engenharia Florestal, v. 19, n. 1, p. 23 - 33, 2012.

FIEDLER, N. C.; ANDRADE, S. C.; MINETTI, L. J.; SOUZA, A. P. Análise de fatores humanos e condições de trabalho em operações de colheita florestal. Revista Árvore, v. 24, n. 2, p. 135 - 142, 2000.

FONTANA, G.; SEIXAS, F. Avaliação ergonômica do posto de trabalho de modelos de "forwarder" e "skidder". Revista Árvore. Viçosa. v. 31, n. 1, p. 71 - 81, 2007.

IIDA, I. Ergonomia: projeto e produção. São Paulo: Edgard Blücher, 1990. 465 p.

Ergonomia: projeto e produção. 2. ed. São Paulo: Edgard Blücher, 2005.

LOPES, E. S.; VOSNIAK, J.; FIEDLER, N. C.; INOUE, M. T. Análise dos fatores humanos e condições de trabalho em operações de implantação florestal. Floresta, Curitiba, v. 41, n. 4, p. 707 - 714, 2011.

MINETTE, L. J.; SOUZA, A. P. de; ALVES, J. U.; FIEDLER, N. C. Estudo antropométrico de operadores de motosserra. Revista Brasileira de Engenharia Agrícola e Ambiental, v. 6, n. 1, p. 166 $170,2002$.

SCHLOSSER, J. F.; DEBIASI, H.; PARCIANELLO, G.; RAMBO, L. Antropometria aplicada aos operadores de tratores agrícolas. Ciência Rural, v. 32, n. 6, p. 983 - 988, 2002.

SILVA, E. P.; MINETTE, L. J.; SOUZA, A. P. Análise ergonômica do trabalho de coveamento semimecanizado para o plantio de eucalipto. Scientia Forestalis, n. 76, p. 77 - 83, 2007.

TOUPIN, D.; LEBEL, L.; DUBEAU, D.; IMBEAU, D.; BOUTHILLIER, L. Measuring the productivity and physical workload of brushcutters within the context of a production-based pay system. Forest Policy and Economics, n. 9, p. 1046 - 1055, 2006. 
